\title{
Internet Addiction among Adolescents: A Review of the Research
}

\author{
Vandana Goswami $^{1 *}$, Dr. Divya Rani Singh ${ }^{2}$
}

\section{ABSTRACT}

The Internet is a new tool that is evolving into an essential part of everyday life all over the world and is use increases especially young people. As the Internet increasingly becomes part of our daily lives, Internet addiction disorder has received much attention. There are several reviews addressing the definition, classification, impact of Internet on India, Internet addiction Test, Gender differences in Internet addiction, academic performance and Internet addiction and some reviews addressing the treatment of Internet addiction disorder. The main aim of this paper is to give a preferably brief overview of research on IAD.

Keywords: Internet Addiction Disorder (IAD), Internet Addiction Test (IAT), Adolescents, Gender Differences

Internet is a global system that is increasingly used by all people as one of the most important devices for access of information in the world. The term "Internet addiction" was proposed by Dr. Ivan Goldberg in 1996 for pathological compulsive Internet use. Over the last couple of years, Internet addiction has been become a global concern to the public and can be classified as a health issue. There is even a proposal to include Internet addiction in the next revision of the Diagnostic and Statistical Manual of Mental Disorder. Addictive behaviours were suggested to cause improper life style and impairment to personalities, especially amongst the young. The education system has evolved and the use of technology is now encouraged at much younger ages.

Internet addiction means the over use of Internet to such extent that our everyday life collapses. At the end it leads to complete breakdown of our personal and social relationship, work and sleep routine as well as our mood and thinking capability. In other words we can say that the over use of Internet creates disturbances in our life. The use of the Internet on school campuses and in society has increased dramatically in recent years. Whereas the academic use of the Internet is primarily intended for learning and research, the Internet has also become an

\footnotetext{
${ }^{1}$ Research Scholar, Department of Home Science, D.D.U. Gorakhpur University Gorakhpur, (U.P.), India

${ }^{2}$ Assistant Professor, Department of Home Science, DDU Gorakhpur University Gorakhpur, (U.P.), India *Responding Author

(C) 2016 I V Goswami, D Singh; licensee IJIP. This is an Open Access Research distributed under the terms of the Creative Commons Attribution License (http://creativecommons.org/licenses/by/2.0), which permits unrestricted use, distribution, and reproduction in any Medium, provided the original work is properly cited.
} 
important part of student life. However, from time to time, cases of over involvement with the Internet have been observed on different campuses.

\section{Definition and Classification of Internet Addiction}

The appropriate classification of Internet addiction has been debated. Some investigators have linked Internet addiction to addictive disorders, grouping it alongside alcohol and drug use disorders (Griffiths 1999). Others have linked Internet addiction to Obsessive-Compulsive disorder (Sussman 2005). Or to the impulse control disorders (Shapira, et al 2000, Young 1998). The many names given to this phenomenon recognize the various ways in which it has been regarded Compulsive computer use (Black, et al 1999), Pathological Internet use (Davis 2001), Problematic Internet use (Caplan 2003), Internet dependency (Schere 1997) and Internet addiction (Goldberg 1996).

There are many definitions available for Internet addiction. In the psychiatric literature, Black, et.al. (1999) described a series of 'compulsive Computer users', the only requirement of which was that subjects acknowledged "Compulsive Computer use that had contributed to personal distress or social, occupational, financial or legal consequences”. . further refined the definition of 'Problematic Internet use' by enumerating operational criteria that emphasize cognitive and behavioral aspects of the disorder, as well as impairment characterized by subjective distress and interference in social or occupational functioning, mania and hypomania should be ruled out as causes of the disorder. These criteria were patterned after those developed by McElory et.al. (1994) for compulsive shopping, considered by many as a disorder of impulse control.

Young (1998) has proposed criteria patterned after the DSM-IV-TR criteria for pathological gambling. In employing her criteria, only non-essential Computer/Internet usage (e.g. nonbusiness or non-academic use) is considered. Internet addiction is present when five or more of the eight criteria are present during the past 6 months and mania has been ruled out as a cause. She further breaks 'Internet addiction' in to five subtypes and suggests that people typically become addicted to a particular application that acts as a trigger for excessive Internet use. According to Young et.al. (2000) Internet addiction is a broad term covering a wide variety of behaviours and impulse control problems. The five subtypes of Internet addiction are as follows:

1- Cybersex addiction- This occurs in individuals who are typically engaged in viewing downloading and trading online pornography or are involved in adult fantasy role-play chat rooms.

2- Cyber- relationship addiction- Addiction to social networking, chat rooms, and messaging to the point where virtual, online friends become more important than real-life relationship with family and friends.

3- Net Compulsions- This subtypes includes a broad category of behaviours, including online gambling, shopping or stock trading. 
4- Information Overload- The World Wide Web has created a new kind of Compulsive behaviour that involves excessive web surfing and database searches. These individuals spend a disproportionate amount of time searching for, collecting and organizing information.

5- Computer addiction- Most computers come equipped with pre-programmed games and people become addicted to playing them at the cost of work performance or family obligations.

\section{Impact of Internet on India}

According to Internet and Mobile Association of India (2013) There has been an explosive growth in the use of Internet not only in India, but also worldwide in the last decade. The population of India is around 1.2 billion as of 2012, of which the number of Internet users (both urban and rural) is around 205 million. It is estimated to increase to 243 million by June 2014, and India will be the second-leading country after China which currently has the highest Internet user base of 300 million. Chandra, et.al (2005) reported that the number of Internet users in India has grown five-fold since 2005. Mobile Internet usage is growing at the rate of nearly $85 \%$ per annum, with nearly $75 \%$ of nonvoice usage being devoted to entertainment, where video and music streaming are major growth activities. The understanding that the Internet use can be a disorder is still in its initial stages in India. There are limited numbers of studies estimating how common the issue of Internet addiction is in India.

In a study carried out by Nalwa and Anand (2004) among school children 16-18 years old in India. Two groups were identified-dependents and non-independents. Significant behavioural and functional usage differences were revealed between the two groups. Dependents were found to delay other work to spent time online, lose sleep due to late night logons and feel life would be boring without internet by dependents were greater than those of non-dependants. On the loneliness measure, significant differences were found between the two groups, with the dependents scoring higher than the non-dependants. Das and Mishra (2013) examined the effect of gender and internet use on adolescent's loneliness in India and they found that internet use had a significant effect upon loneliness where as gender had no significant effect upon adolescent`s loneliness. Yadav, et.al. (2013) explored the internet addiction amongst Indian school students and they found that sixty five (11.8\%) students had Internet Addicted; it was predicted by time spent online, usage of social networking sites and chat rooms and also by presence of anxiety and stress. Kodvanji, et.al. (2014) investigated the impact of internet use on lifestyle of undergraduate medical students in India. Their cross-sectional study involved 90 (1820 years) undergraduate medical students. The two groups addictive and non-addictive were compared for environmental stressors and lifestyle factors such as sleep, dietary pattern, physical activities and hobbies. The addictive internet user group had a statistically significant impairment of sleep and excessive day time sleepiness and presence of environmental stressors when compared to the non-addictive internet user group. 


\section{Rating Scales / Test for Internet Addiction Disorder (IAD)}

The Internet Addiction Test (IAT) of Kimberly Young (1998) was the first validated instrument to assess Internet addiction. The IAT is a 20 item, 6 point Likert scale with scores ranging from 0-5 for each item. It measures Internet addiction in mild, moderate and severe addicted level. Brenner (1997) developed the Internet Addictive Behavior Inventory (IRABI) a 32-item questionnaire that probes a user's Internet experiences, modeled after the section on substance abuses in DSM-IV-TR. The instrument was reported to display good Internet consistency but no other information was provided. Morahan-Martin and Schumacher (2000) developed a 13item scale to assess problems associated with Internet use, including personal distress, academic work or inter personal issues, withdrawal symptoms or mood disturbance.

\section{Gender differences in Internet Addiction}

The issue of gender in regard to the question of Internet use and its effects is an important one. Do men and women use the Internet differently and engage different Internet applications? Young (1998) observed that men tend to seek out dominant activities or content online. Those interactive online games that rely particularly on power, dominance, control, and/or violence attract more men than women. Women, on the other hand, seek out close friendships and prefer anonymous communication in which they can hide their appearances. Virtual communities give women a sense of belonging and the ability to share their feelings and emotions in private and convenient ways. Whereas men tend to explore sexual fantasies online, women tend to look for romance in cyberspace. Young states that although it is not unusual for women to engage in random cybersex or cyber sex chat, they often prefer to form some type of relationship prior to the sexual chat. Lin and Yu (2008) reported that males tended to consider the Internet more as a 'toy' but females tended to view it as a tool or technology with which to accomplish task. Bernauy, et.al. (2009) stated that problematic Internet use by students to be lower in the female students compared to males. Razieh, et.al. (2012) examined the prevalence of internet addiction among the universities girl's and boy's students, the result of their study demonstrated that prevalence of internet addiction among boy's students in universities; boys were more addicted than girls.

\section{Academic performance and Internet Addiction}

Canales, et.al. (2009) explored that an extended presence on facebook can have harmful effects on productivity and task performance. Long hours spent on facebook seem to decrease student's academic performance and thus their grades. Dill (2009) observed that children spend more time watching television and movies, playing video games and surfing the Internet than they spend in school per year. Singh and Barmola (2015) reported that the students who were in the severe and profound groups of internet addiction were found to have detrimental effects on both in their academic performance and mental health rather than the students who were addicted to the internet usage moderately. 
Internet Addiction among Adolescents: A Review of the Research

\section{Treatment for Internet Addiction}

Since Internet addiction was first introduced in the media and research literature, many research studies have been undertaken in an attempt to define, explore, investigate and predict addiction and identify possible interventions or treatments for IA. Seven possible interventions have been identified as well as therapeutic approaches such as Cognitive Behavioral Therapy (CBT), Reality Therapy Group Counseling etc.

Young (1999) introduced that the seven possible treatment technique to address Internet Addiction are composed of-:

1- Practice the opposite: After reorganizing one's excess use time online, construct a new reduced schedule or time pattern for using the Internet.

2- External stoppers: Use concrete things (e.g., time to work, to meet boss, etc.) the addict needs to do, or places to go, as prompters to help log off.

3- Setting goals: Set clear and achievable goals to help develop new tangible Internet-use schedules; prevent cravings, withdrawal and relapse; and give the addict a sense of control.

4- Reminder cards: Use tangible, portable reminders of what addicts want to avoid (e.g., lost time with family) and what they want to do (e.g., improved productivity at work).

5- Personal inventory: Generate a list of every activity or practice that has been neglected or curtailed since the online habit emerged.

6- Social support: Organize support groups tailored to addict's particular life disrupted situations to decrease their dependence on online cohorts.

7- Family therapy: Arrange therapy for those addicts whose marriages and family relationships are disrupted and negatively influenced by Internet addiction.

Yang and Hao (2005) investigated the effect of the seven interventions among 52 adolescents in China. The researchers found that IA scored and length of time online significantly decreased after three months of the treatment. Kim (2008) suggested that Reality Therapy Group Counseling as a way of addressing Internet Addiction. The reality therapy is based on choice theory, which views individuals as completely responsible for their own lives. The reality therapy aims to encourage individuals to improve their lives by committing to changing their Internet related behaviours. The therapy includes sessions that help clients understand that addiction is a choice, aids with the learning of proper time management skills, and introduces alternative activities to the addictive behaviour. Shek, et.al. (2009) described an indigenous multi-level counseling program designed for young people with internet addiction problems based on the responses of 59 clients. Regarding objective outcome evaluation, pre-test and posttest data generally showed that the internet addiction problems of the participants decreased after joining the program and there were some slight positive changes in parenting attributes. Participants generally perceived that the program was helpful. Du, et.al. (2010) investigated that randomized, controlled trial for the treatment of Internet addiction in adolescents. Their study 
involved a multimodal school-based intervention involving eight sessions of group-based Cognitive Behavioral Therapy (CBT). Therapy involved addicted adolescents learning principles of effective communication with their parents, learning how to manage online relationships, techniques for controlling impulses, and techniques for recognizing and stopping problematic behaviour. Parent training was also delivered in tandem, and this involved teaching parents to recognize their child's emotions, increase problematic solving and communication between family members and develop techniques for managing adolescents with problem technology use. Psycho education was also delivered to teachers in the school. Post treatment, adolescents significantly reduced their Internet use and anxiety and improved their time management skills. Treatment gains were maintained at 6-month follow-up.

\section{CONCLUSION}

Excessive use of the Internet has become one of the leading challenges of the modern society and causes both physical and mental impairment. On the basis of this review paper we have understand that Internet has become one of the most significant information resources for adolescents, its impact is remarkable. It makes countless disturbances in academic performance; social relationship, emotional wellbeing etc. so we should control the over use of Internet, and try to follow treatment techniques for Internet addiction.

\section{REFERENCES}

Bernyauy M., Oberst U, Carbonell X., Chamarro, A. (2009) Problematic internet and mobile phone use and clinical symptoms in college students: The Role of Emotional Intelligence, Computers in Human Behavior, 25 (5), 1182-1187.

Black, D.W., Belsare, G., Schlosser, S., (1999). Clinical features, psychiatric co morbidity and health-related quality of life in persons reporting compulsive computer use behavior. $J$ Clin Psychiatry, 60: 839-43.

Brenner, V. (1997). Psychology of computer use: XLVII Parameters of Internet use abuse and addiction: the first 90 days of the Internet usage survey. Psych Rep, 80: 879-82.

Canales, C., Wilbanks, B., Yeoman, A. (2009). Does Facebook have negative impacts on academic performance? Facebook usage in relation to personality and academic performance. http://www.covenant.edu/news/09.28.09

Caplan, S.E. (2003). Preference for online social interaction: a theory of problematic internet use and psychosocial well-being. Comm Research, 30: 625-48.

Chandra G., Anu M., Noshir K., James M. (2012). Online and upcoming: The Internet's impact on India. Bangalore: McKinsey \& Company, 1-3

Das, P.P.P. and Mishra, C. (2013). Adolescent's Loneliness: Effect of Gender and Internet use. Asian Journal of Research in Social Sciences and Humanities, 3 (9), 232-242.

Davis, R. (2001). A cognitive behavioral model of pathological internet use. Comput Human Behav, 17: 187-95. 
Dill, K.E. (2009). How fantasy becomes reality: seeing through media influence. New York: Oxford University Press.

Du, Y., Jiang, W., Vance, A. (2010). Longer term effect of randomized, controlled group cognitive behavioral therapy for internet addiction in adolescent student in Shanghai. Australian and Newzealand Journal of Psychiatry, 44, 129-134.

Goldberg, I. (1996). Internet addiction disorder [online]. Available from URL: http://www.cog.brown.edu/broucher/people/duchon/humor/internet.addiction.

Griffiths, M.D. (1999). Internet addiction: fact or fiction? Psychologist, 12: 246-51.

Internet and Mobile Association of India (2013). Internet Users in India Crosses 200 Million Mark. New Delhi: Internet and Mobile Association of India (IMAI)

Kim, J.H. (2008). The effect of a R/T Group counseling program on the internet addiction level and self-esteem of internet addiction university students. International Journal of Reality Therapy, 27 (2), 4-12.

Kodvanji, B., Chathoth, V., Kumar, N.A., Kini, R.D., Pai, S.R. (2014). Impact of Internet use on lifestyle in undergraduate medical students. International Journal of Biomedical Research, 5 (3).

Lin, C.H., and Yu, S.F. (2008). Adolescent internet usage in Taiwan: Exploring gender differences. Journal of Adolescence, 43 (170), 317-331.

Marahan-Martin J., Schumacher P. (2000). Incidence and correlation of pathological internet use among college students. Comput Human Behav, 16: 13-29.

McElory, S.L., Keck, J.R., Harrison, P.G., et al (1994). Compulsive buying: a report of 20 cases. J Clin Psychiatry, 55: 242-8.

Nalwa, K. and Anand, A.P. (2004). Internet Addiction in Students: A cause of Concern. CyberPsychology and Behavior, 6 (6), 653-656.

Razieh, J., Ali, G., Zaman, A. (2012). The Relationship between Internet Addiction and Anxiety in the Universities Students. INTERDISCIPLINARY JOURNAL OF CONTEMPORARY RESEARCH IN BUSINESS, 4, 1.

Schere, K. (1997). College life on-line: healthy and unhealthy internet use. J College Student Dev, 38: 655-65.

Shapira, N., Goldsmith, T., Keckjr, P., et al. (2000). Psychiatric features of individuals with problematic internet use. J Affect Disord, 57: 267-72.

Shek, D.T.L., Tang, V.M.Y., Lo, C.Y. (2009). Evaluation of an Internet addiction treatment program for Chinese adolescent's in Hong Kong. Adolescence, 44 (174), 359-373.

Singh, N. and Barmola, K.C. (2015). Internet Addiction, Mental Health and Academic Performance of School Students/Adolescent. The International Journal of Indian Psychology, 2 (3).

Sussman, N. (2005). Session with Eric Hollander, M.D. Interview, New York city [online] http:// www.primarypsychiatry.com/aspx?article_260 


\section{Internet Addiction among Adolescents: A Review of the Research}

Yadav, P., Banwari, G., Parmar, C., Maniar, R. (2013). Internet addiction and its correlates among high school students: A Preliminary study from Ahmadabad, India. Asian Journal of Psychiatry, 6 (6), 500-506.

Yang, F., Hao, W. (2005). The effect of integrated psychosocial intervention on 52 adolescents with internet addiction disorder. Chinese Journal of Clinical Psychology, 13 (5), 343345.

Young, K. (1998) Internet addiction: the emergence of a new clinical disorder. Cyberpsychol Behav, 3: 237-44.

Young, K. (1999). Internet addiction: symptoms, evaluation and treatment. InL. Vandecreek \& T. Jackson (Eds.), Innovations in Clinical Practices: A Source Book, 17, 19-31. Sarasota, FL: Professional Resource Press.

Young, K., Pistner, M., et al (2000). Cyber-disorders: the mental health concern for the new millennium. Cyberpsychol Behav, 3: 475-9.

How to cite this article: V Goswami, D Singh (2016), Internet Addiction among Adolescents: A Review of the Research, International Journal of Indian Psychology, Volume 3, Issue 3, No. 11, DIP: 18.01.194/20160303, ISBN: 978-1-365-21307-6 